\title{
Catheter Associated Blood Stream Infection (CLABSI) - Bacteriological Profile and Antibiotic Susceptibility Pattern in NNICU of a Tertiary Care Hospital in Andhra Pradesh, India
}

\author{
Nazeema Tabaseera and Sreedevi Hanumantha* \\ Kodagu Institute of Medical Sciences, Madikeri, India \\ *Corresponding author
}

Ke y w o r d s
CLABSI, CVC, CL,
Paired specimens,
ICU, NNICU
Article Info
$\begin{aligned} & \text { Accepted: } \\ & 26 \text { June } 2018 \\ & \text { Available Online: } \\ & \text { 10 July } 2018\end{aligned}$

\section{A B S T R A C T}

There are very few studies on CLABSI in NNICU. Surveillance of CLABSI in NNICU is integral, as it provides insight to health care workers to work towards declining its rate and its unsavory consequences, via implementation and adherence to specific care bundles. Objectives of the study are: 1) To find the incidence of CLABSI in NNICU patients; 2) To identify etiological agents responsible for CLABSI; 3) To determine antimicrobial susceptibility pattern for bacterial agents obtained. Paired specimens, namely, distal end of central line and peripheral venous blood from suspected cases of CLABSI were subjected to culture and sensitivity test. Diagnosis of CLABSI was made when same strain of bacterium was obtained from both specimens along with significant bacterial count from catheter tip. Central line was inserted in 75 patients during the study period with 433 central line (CL) days with an average of 12-16 CL days per patient. 9(12\%) out of 25 patients suspected of CLABSI yielded positive cultures. The CLABSI rate was 20.8 per 1000 central line days. The central line utilization rate was 0.3. E coli was the most predominant pathogen, followed by CoNS and Enterobacter. Most effective antimicrobial agents for Enterobacteriaciae group were colistin, gentamicin, imipenam and meropenam. CoNS and Pseudomonas were susceptible to all antimicrobial agents tested including simple ones, namely, ampicillin and cefipime respectively.

\section{Introduction}

Neurology and neurosurgery ICU (NNICU) is one of the important subspecialties of medicine, aimed to provide effective therapeutic modalities to patients with lifethreatening neurological diseases ${ }^{1}$. Infectious complications in the NNICU patient population can be classically listed as meningitis, ventriculitis, encephalitis, brain abscess, and subdural or epidural empyema, which are frequently associated with invasive procedures specific to neurology, viz., craniotomy or placement of intracranial devices for the purpose of monitoring intracranial pressure (ICP) or for diversion of the cerebrospinal fluid (CSF) from an obstructed ventricular system etc $^{2-3}$. Apart from these, there also occur infections in NNICUs that are common to all ICUs. The 
most notable ones are device associated infections as a result of utilization of urinary catheters, vascular lines and ventilators ${ }^{4}$. Among these, central line associated blood stream infection (CLABSI) is one of the significant device associated infections. On one hand, CLABSI contributes to significant morbidity, mortality and additional cost among hospitalized patients ${ }^{5}$, on the other it is recognized as a preventable healthcare associated infection(HAI $)^{6,7}$. Surveillance of CLABSI is integral, as it provides insight to health care workers to work towards declining its rate and its unsavory consequences, via implementation and adherence to specific care bundles $^{7-9}$. CLABSI rates are much higher in NNICUs in comparison with other ICUs ${ }^{10-12}$. However, since there are scarce data on CLABSI in NNICU in this part of region, this study was taken up.

\section{Materials and Methods}

This is a prospective study carried out in a tertiary care hospital situated at Visakhapatnam, Andhra Pradesh, India for the period of 6 months from January 2016 to June 2016. Approval of Institutional Ethical Committee was taken. A total of 75 patients admitted in the NNICU with central venous catheter (CVC) /central line (CL) were considered in this study.

\section{Inclusion criteria}

1. Patients with CVC for more than 48 hours.

2. Patients with provisional diagnosis of blood stream infection based on clinical suspicion.

3. Patients in whom CVC was removed/changed, so that catheter tip was available for test.

\section{Exclusion criteria}

Patients with known focus of infection other than CVC.

In a proforma detailed history of the patients was recorded in regard with demography, hospital stay, co-morbidities, neurological diagnosis, and date of insertion and removal of CL, laboratory tests and reports. CLABSI rate was calculated as CLABSIs/1000 CL days and device utilization ratio as number of device days/number of patient days.

\section{Specimen collection and transport}

Paired specimens were collected from each patient under aseptic condition. CLs were removed aseptically and then the first sample, namely, the distal $5 \mathrm{~cm}$ of the catheter was amputated with a sterile surgical scalpel and collected in sterile container ${ }^{13}$. Secondly, 10$20 \mathrm{ml}$ peripheral venous blood was collected and inoculated in BHI broth. Appropriately labeled specimens were transported to Microbiology laboratory immediately for processing.

\section{Processing of specimens in the Microbiology laboratory}

Distal end of CL was rolled over blood agar. The media was incubated at $37^{\circ} \mathrm{C}$ for 24 hours under aerobic condition. Colony count more than 15 was considered significant ${ }^{13}$. Similarly, BHI broth was incubated at $37^{\circ} \mathrm{C}$ under aerobic condition for one week. Subculture onto blood agar and MacConkey agar was done on alternate days or whenever turbidity appeared. Identification of bacterial agent was done based on standard laboratory procedures ${ }^{14}$. Antibiotic sensitivity test was done according to Kirby Bauer method using antibiotic discs as per CSLI guidelines. Diagnosis of CLABSI was made when same strain of bacterium was obtained from catheter 
tip and blood culture based on identical antimicrobial sensitivity profiles provided there was significant bacterial count from catheter tip.

\section{Results and Discussion}

CVCs was inserted in 75 patients during the study period with 433 CLdays with an average of 12-16 (mean duration of $16.2 \pm 10$ days) CL days per patient. Among them 25 patients were suspected of having blood steam infection due to presence of CVC. However, only $9(12 \%)$ patients yielded positive cultures in paired sample. The CLABSI rate was 20.8 per $1000 \mathrm{CL}$ days. The central line utilization rate was 0.31. Samples from all 9 patients yielded single etiological agent. The spectrum of bacterial isolates is depicted in table 1 .

Gram negative bacteria were predominant contributing to $78 \%$ of CLABSI and rest 22\% is caused by CoNS. E. coli was found as most predominant pathogen, followed by CoNS and Enterobacter, there after came Pseudomonas aeruginosa and Klebsiella spp.

Antimicrobial susceptibility pattern of Enterobacteriaceae is shown in table 2. All GNBs belonging to Enterobacteriaceae were sensitive to colistin, gentamicin, imipenam and meropenam. 5 were sensitive to amikacin, doripenam, levofloxacin. 4 were sensitive to ampicillin/sulbactam, cefipime, ciprofloxacin, piperacillin-tazobactam, 3 were sensitive to amoxyclav, aztreonam, cefotaxime, ceftazidime and 2 were sensitive to ampicillin, cefaperazone, ceftriaxone, cotrimoxazole.

Antimicrobial profile of $\boldsymbol{P}$ aeruginosa, a non-fermenting Gram negative bacteria

One isolate of $P$. aeruginosa was sensitive to all the antibiotics tested, viz amikacin, aztreonam, cefipime, ceftazidime, ciprofloxacin, doripenam, gentamicin, imipenam, levofloxacin, meropenam, piperacillin, piperacillin/tazobactam and polymyxin-B.

\section{Antimicrobial profile of Gram positive cocci}

2 isolates of CoNS were found to be methicillin sensitive. CoNS was found sensitive to most of the antibiotics tested, namely, ampicillin, amoxicillin, ampicillin/ sulbactam, amoxyclav, cefaperazone, cefipime, cefixime, cefotaxime, ceftriaxone, ciprofloxacin, cotrimoxazole, amikacin, gentamicin, linezolid, tigecyclin, teicoplanin and vancomycin.

Table.1 The spectrum of bacterial isolates of CLABSI

\begin{tabular}{|l|c|}
\hline Organism & Frequency $(\mathrm{n}=9)$ \\
\hline Escherichia coli & 3 \\
\hline Enterobacter & 2 \\
\hline Coagulase negative & 2 \\
\hline Staphyococcus & 1 \\
\hline Klebsiella species & 1 \\
\hline P. aeruginosa & \\
\hline
\end{tabular}


Table.2 Antimicrobial susceptibility pattern of Enterobacteriaceae

\begin{tabular}{|c|c|c|}
\hline Antimicrobial drug & Sensitive & Resistant \\
\hline Ampicillin & 2 & 4 \\
\hline Ampicillin/sulbactam & 4 & 1 \\
\hline Amoxyclav & 3 & 2 \\
\hline Amikacin & 5 & 1 \\
\hline Aztreonam & 3 & 3 \\
\hline Cefipime & 4 & 2 \\
\hline Cefoperazone & 2 & 4 \\
\hline Cefotaxime & 3 & 3 \\
\hline Ceftriaxone & 2 & 4 \\
\hline Cetazidime & 3 & 3 \\
\hline $\begin{array}{l}\text { Cetazidime/Clavulinic } \\
\text { acid }\end{array}$ & 3 & 3 \\
\hline Ciprofloxacin & 4 & 2 \\
\hline Cotrimoxazole & 2 & 4 \\
\hline Colistin & 6 & - \\
\hline Doripenam & 5 & 1 \\
\hline Gentamicin & 6 & - \\
\hline Imipenam & 6 & - \\
\hline Meropenam & 6 & - \\
\hline Levofloxacin & 5 & 1 \\
\hline Piperacillin-tazobactam & 4 & 2 \\
\hline
\end{tabular}


Device associated infections contribute to $14.7 \%$ of infections among all ICUs including NNICUs ${ }^{15}$. Around $60 \%$ of all types of nosocomial bacteremia are originated from one or other form of vascular access ${ }^{16}$. About $87 \%$ of bloodstream infections (BSI) are said to be because of indwelling vascular catheters 17. BSI are higher with CL than with peripheral lines ${ }^{18}$. Risk factors for CLABSI include insertion of CVC in ICU, duration of central access, receipt of blood transfusion and parenteral nutrition, presence of gastrostomy tube, drains and nonoperative medical conditions ${ }^{19}$. CLABSIs forms $30 \%$ of all device-associated infections preceded by VAP( $41 \%)$, followed by CAUTI $(29 \%)^{15}$. CLABSIs are one of the most dangerous HAIs, with a mortality rate up to $25 \%{ }^{20}$.

CLABSI is a laboratory-confirmed bloodstream infection (LCBI) where CL or umbilical catheter was in place for $>2$ calendar days on the date of event, with day of device placement being Day 1, AND the line was also in place on the date of event or the day before. If a CL or UC was in place for $>2$ calendar days and then removed, the date of event of the LCBI must be the day of discontinuation or the next day to be a CLABSI $^{21}$. Surveillance of baseline CLABSIs plays an important role in strengthening infection control practices and further to reduce and prevent them. The baseline CLABSI rate in different ICUs was 6.4 CLABSIs per 1000 CL-days in India ${ }^{10}$. It was 10.7 per 1,000 CL days among pediatric ICUs of 5 developing countries including India ${ }^{11}$. It was found to be 2.5 per $1000 \mathrm{CL}$ days in oncology ICUs ${ }^{22}$. However, its incidence is reported to be much higher (20.7) in $\mathrm{NNICU}^{12}$. One review article portrays that the CLABSI rate in limited-resource countries ranged from 1.6 to 44.6 per $1000 \mathrm{CL}$ days in adult and pediatric intensive care units (ICUs) and from 2.6 to 60.0 per $1000 \mathrm{CL}$ days in neonatal $\mathrm{ICUs}^{23}$.
In our study that was conducted in NNICU at Visakhapatnam, situated in a lap of South India, CLABSI rate was 20.8 per $1000 \mathrm{CL}$ days which is strikingly similar to the work done in similar setting in Delhi, the heart of North India, recently which was 20.6 per $1000 \mathrm{CL}$ days $^{12}$. In medical-surgicalneurosurgical ICUs of Mexican public hospitals, overall rate of CR-BSIs was 23.1 per 1000 device days ${ }^{24}$. However, it was 1.9 per 1,000 CL days, a much lower rate in neurological ICU, Germany ${ }^{25}$. In this study, $E$. coli was the most predominant pathogen, followed by CoNS and Enterobacter which is similar to the study conducted in multiple developing countries ${ }^{15}$. Jaggi $\mathrm{N}$ and colleagues quoted Klebsiella as predominant pathogen $^{10}$. However, CoNS was predominant causative agent, which was followed by bacteria belonging to Enterobacteriaceae family in other studies ${ }^{4,12,17}$. In our study, fortunately there were no ESBLs or Methicillin resistant Staphylococcus unlike other studies ${ }^{15}$. Patients' response to antimicrobials that were administrated based on culture sensitivity reports was good in terms of curbing CLABSI, but it was not entire as there were underlying neurological disorders along with other co-morbid conditions.

It is concluded according to our knowledge, CLABSI rate is higher in NNICU compared to general ICUs and other superspeciality ICUs namely pediatric, neonatal and oncology ICUs.

\section{References}

1. Rincon Fred, Mayer SA. Neurocritical care: a distinct disciple?. Current opinion in Critical care. 2007;13(2):115-21.

2. Beer R, Lackner P, Pfausler $B$ and Schmutzhard E. Nosocomial ventriculitis and meningitis in neurocritical care patients. J Neurol. 2008; 255(11):1617- 
24.

3. Ziai WC, Lewin JJ. Advances in the management of central nervous system infections in the ICU. Crit Care Clin. 2006; 22:661-94.

4. Weinstein RA, Darouiche RO. DeviceAssociated Infections: A Macroproblem that starts with Microadherence. Clin Infect Dis. 2001; 33(9):1567-72

5. Klevens RM, Edwards JR, Richards CL, Horan TC, et al., Estimating health careassociated infections and deaths in U.S. hospitals, 2002. Public Health Rep. 2007; 122(2):160-6.

6. Pronovost P, Needlam D, Berenholtz S and Sinopoli D. An intervention to decrease catheter-related bloodstream infections in the ICU. N Engl J Med. 2006; 355(26):2725-32.

7. Jeong IS, Park SM, Lee JM, Song JY, et al., Effect of central line bundle on central line-associated bloodstream infections in intensive care units. Am J Infect Control. 2013; 41(8): 710-6.

8. Zimlichman E, Henderson D, Tamir O, Franz C, et al., Health care-associated infections: a metaanalysis of costs and financial impact on the U.S. health care system. JAMA Intern Med. 2013; 173(22): 2039-46.

9. O'Grady NP, Alexander M, Burns LA, Dellinger EP, et al., Guidelines for the prevention of intravascular catheterrelated infections. Am J Infect Control. 2011; 39(4 Suppl 1): S1-34.

10. Jaggi N, Rodrigues C, Rosenthal VD, Todi SK, et al., Impact of an International Nosocomial Infection Control Consortium multidimensional approach on central line-associated bloodstream infection rates in adult intensive care units in eight cities in India. Int J Infect Dis. 2013; 17(12): e1218-24

11. Rosenthal VD, Ramachandran B, Villamil-Gómez W, Armas-Ruiz A, et al., Impact of a multidimensional infection control strategy on central lineassociated bloodstream infection rates in pediatric intensive care units of five developing countries: findings of the International Nosocomial Infection Control Consortium (INICC). Infection. 2012; 40(4): 415-23.

12. Mehndiratta MM, Nayak R, Ali S and Sharma A. Bloodstream infections in NNICU: Blight on ICU stay. Ann Indian Acad Neurol. 2016; 19(3): 327-31

13. Maki DG, Weise CE and Sarafin HW. A semiquantitative culture method for identifying intravenous-catheter-related infection. N Engl J Med. 1977; 296(23): 1305-9.

14. Forbes BA, Sahm DF, Weissfeld AS. Bailey and Scott's Diagnostic Microbiology. $12^{\text {th }}$ ed. Philadelphia; Mosby Elseveir; 2007.

15. Rosenthal VD, Maki DG, Salomao R, Moreno CA, et al., Device-Associated Nosocomial Infections in 55 Intensive Care Units of 8 Developing Countries. Ann Intern Med. 2006; 145(8):582-591.

16. Crnich CJ, Maki DG. The role of intravascular devices in Sepsis. Curr Infect Dis Rep 2001; 3:496-506.

17. Richards MJ, Edwards JR, Culver DH and Gaines RP. Nosocomial infections in medical intensive care units in the United States. National Nosocomial Infections Surveillance System. Crit Care Med., 1999; 27:887-92.

18. Maki DG, Kluger DM, Crnich CJ. The risk of bloodstream infection in adults with different intravascular devices: a systematic review of 200 published prospective studies. Mayo Clin Proc. 2006; 81: 1159-71.

19. Wylie M., Graham DA., Potter-Bynoe G, Kleinman M., et al., Risk Factors for Central Line-Associated Bloodstream Infection in Pediatric Intensive Care Units. Infect Control Hosp Epidemiol. 
2010; 31(10): 1049-56.

20. O'Grady NP, Alexander M, Dellinger EP, Gerberding JL. Guidelines for the prevention of intravascular catheterrelated infections. MMWR 2002; 51(RR10):1-26.

21. www.cdc.gov/nhsn/pdfs/pscmanual/4psc clabscurrent.pdf

22. Mollee P, Jones M, Stackelroth J, van Kuilenburg R, et al., Catheter-associated bloodstream infection incidence and risk factors in adults with cancer: a prospective cohort study. J Hosp Infect 2011; 78(1): 26-30.

23. Rosenthal VD. Central Line-Associated
Bloodstream Infections in LimitedResource Countries: A Review of the Literature. Clin Infect Dis. 2009; 49(12): 1899-907.

24. Ramirez Barba EJ, Rosenthal VD, Higuera F, Oropeza MS, et al., Deviceassociated nosocomial infection rates in intensive care units in four Mexican public hospitals. Am J Infect Control. 2006; 34(4): 244-7.

25. Dettenkofer M, Ebner W, Els T, Babikir $\mathrm{R}$, et al., Surveillance of nosocomial infections in a neurology intensive care unit. J Neurol. 2001; 248: 959-64.

\section{How to cite this article:}

Nazeema Tabaseera and Sreedevi Hanumantha. 2018. Catheter Associated Blood Stream Infection (CLABSI) - Bacteriological Profile and Antibiotic Susceptibility Pattern in NNICU of a Tertiary Care Hospital in Andhra Pradesh, India. Int.J.Curr.Microbiol.App.Sci. 7(07): 3935-3941. doi: https://doi.org/10.20546/ijcmas.2018.707.457 